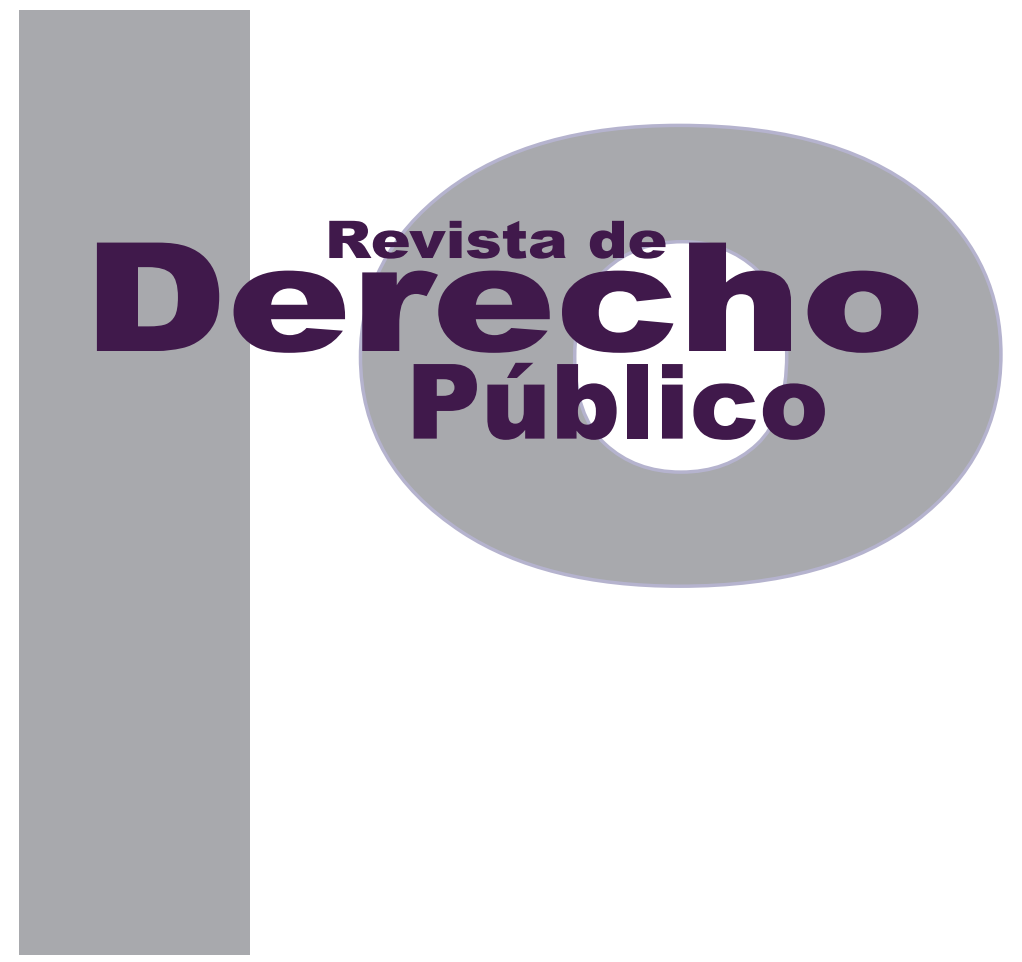

\title{
COMPITIENDO CONTRA TODO: INTERVENCIÓN CIUDADANA EN EL CASO DE DOS ATLETAS PARALÍMPICOS ANTE LA CORTE CONSTITUCIONAL. IMPLICACIONES PARA LA MATERIALIZACIÓN DEL MODELO SOCIAL DE LA DISCAPACIDAD EN COLOMBIA
}

\author{
TATIANA URIBE MARIÑo
}

Reporte de caso

Universidad de los Andes

Facultad de Derecho

Revista de Derecho Público N. ${ }^{\circ} 32$

Enero - Junio de 2014. ISSN 1909-7778 


\title{
Compitiendo contra todo: intervención ciudadana en el caso de dos atletas paralímpicos ante la Corte Constitucional. Implicaciones para la materialización del modelo social de la discapacidad en Colombia
}

\section{Resumen}

El documento tiene como finalidad presentar el contexto normativo, delimitar el contenido y analizar la incidencia en la decisión final, de la intervención presentada por el Programa de Acción por la Igualdad y la Inclusión Social (PAlls), a solicitud de la Corte Constitucional, en el caso de los expedientes n.os T-3672842 y T-3754187 acumulados, consistentes en acciones de tutela instauradas por Luis Antonio Pérez Covos y Marcos Omar Suárez Piragauta, dos atletas paralímpicos que han representado al país en competencias nacionales e internacionales de tiro deportivo y natación, contra el Departamento Administrativo del Deporte, la Recreación, la Actividad Física y el Aprovechamiento del Tiempo Libre (Coldeportes), las cuales dieron lugar a la sentencia T-287 de 2013, proferida por la Sala Sexta de revisión de la Corte Constitucional. La autora de este trabajo realizó la investigación y redacción del amicus curiae que fue presentado ante la Corte bajo la supervisión del equipo asesor de pAlls.

Palabras clave: Discapacidad, deporte, persona con discapacidad, modelo social de discapacidad, ajustes razonables, derechos humanos, accesibilidad, discriminación por motivos de discapacidad, Convención sobre los Derechos de las Personas con Discapacidad.

\section{Battling against everything: Community's intervention in a case regarding two paralympic athletes in face of the Constitutional Court. Implications for the execution of the social model of disability in Colombia}

\begin{abstract}
The document is entended to present normative context, delimit the content and analyze the impact of the final decision, from the intervention made by PAIIS which was requested by the Constitutional Court, in records No. T-3672842 and T-3754187 that were cases accumulated, which consist in protective actions complaint and made by Luis Antonio Pérez and Marcos Omar Suárez Covos Piragauta, two paralympic athletes who have represented the country in national and international competitions like shooting sport and swimming, against the Administrative Department of Sport, Recreation, physical Activity and Use of Free Time (Coldeportes), which gave rise to the judgment T-287 of 2013, issued by the Sixth Court of review of the Constitutional Court. The author of this paper made the research and writing of amicus curiae which was presented to the Court under the supervision of the consultant team, PAlls.

Keywords: Disability, sport, persons with disabilities, social model of disability, reasonable accommodation, human rights, accessibility, discrimination on the basis of disability, Convention on the Rights of Persons with Disabilities.

\section{Competindo contra tudo: intervenção cidadã no caso de dois atletas paraolímpicos ante a Corte Constitucional. Implicações para a materialização do modelo social da deficiência na Colômbia}

Resumo

O documento tem como finalidade apresentar o contexto normativo, delimitar o conteúdo e analisar a incidência na decisão final, da intervenção apresentada pelo Programa de Ação pela Igualdade e a Inclusão Social (PAlIs), a solicitação da Corte Constitucional, no caso dos expedientes n. ${ }^{0 s}$ T-3672842 e T-3754187 acumulados, consistentes em ações de tutela instauradas por Luis Antonio Pérez Covos e Marcos Omar Suárez Piragauta, dois atletas paraolímpicos que têm representado o país em competições nacionais e internacionais de tiro esportivo e natação, contra o Departamento Administrativo do Deporte, a Recreação, a Atividade Física e o Aproveitamento do Tempo Livre (Coldeportes), as quais deram lugar à sentença T-287 de 2013, proferida pela Sala Sexta de revisão da Corte Constitucional. A autora deste trabalho realizou a pesquisa e redação do amicus curiae que foi apresentado ante a Corte sob a supervisão da equipe assessora de pAlls.

Palavras-chave: Deficiência, deporte, pessoa com deficiência, modelo social de deficiência, ajustes razoáveis, direitos humanos, acessibilidade, discriminação por motivos de deficiência, Convenção sobre os Direitos das Pessoas com Deficiência. 


\section{SUMARIO}

Introducción - I. APROXIMACIONES CONCEPTUALES A LA DISCAPACIDAD Y EVOLUCIÓN DEL MARCO INTERNACIONAL DE LOS DERECHOS HUMANOS SOBRE LAS PERSONAS CON DISCAPACIDAD - A. Modelo de prescindencia - B. Modelo de rehabilitación o médico - C. Modelo social - D. Evolución del marco internacional de derechos humanos sobre discapacidad - II. EL CASO CONCRETO, INTERVENCIÓN CIUDADANA Y DECISIÓN DE LA CORTE - A. Acciones de tutela presentadas - $B$. Intervención ciudadana - C. Sentencia T-287 de 2013 - III. CONCLUSIONES - Bibliografía. 


\section{Compitiendo contra todo: intervención ciudadana en el caso de dos atletas paralímpicos ante la Corte Constitucional. Implicaciones para la materialización del modelo social de la discapacidad en Colombia ${ }^{1}$}

\section{Tatiana Uribe Mariño²}

Introducción

Luis Antonio Pérez Covos y Marcos Omar Suárez Piragauta son dos atletas paralímpicos que han representado al país en competencias nacionales e internacionales de tiro deportivo y natación. Los dos interponen, por separado, acciones de tutela contra el Departamento Administrativo del Deporte, la Recreación, la Actividad Física y el Aprovechamiento del Tiempo Libre (Coldeportes) por no permitirles competir en eliminatorias con menos de tres competidores.

La Corte Constitucional solicitó una intervención experta del Programa de Acción por la Igualdad y la Inclusión Social (PAlls) en estos dos casos, que decidió acumular. La autora del presente

1 Como citar este artículo: Uribe Mariño, T. (Junio, 2014). Compitiendo contra todo: intervención ciudadana en el caso de dos atletas paralímpicos ante la Corte Constitucional. Implicaciones para la materialización del modelo social de la discapacidad en Colombia. Revista de Derecho Público, 32.

2 Abogada de la Universidad de los Andes. Coordinadora de la especialización en Legislación Financiera de la Universidad de los Andes. Miembro de la ong Pares en Acción Reacción contra la Exclusión Social (PARCES). Correo: at.uribe1715@ gmail.com trabajo realizó, bajo la supervisión del equipo asesor de palls, la investigación y redacción del amicus curiae que fue presentado ante la Corte.

Palls es una clínica de derecho de interés público, de la Facultad de Derecho de la Universidad de los Andes. Inició sus actividades en el año 2007 con el fin de promover los derechos de las personas de especial protección constitucional en Colombia. Su trabajo se ha centrado principalmente en la defensa y promoción de los derechos de las personas con discapacidad, personas mayores y personas discriminadas en razón de su orientación sexual o identidad de género. PAlls realiza acciones de litigio estratégico; apoyo técnico en el diseño e implementación de políticas públicas; pedagogía en derechos; asesoría legal; intervenciones ante instancias nacionales, regionales e internacionales y formación en el ejercicio del derecho de interés público. Adicionalmente, trabaja en red con la academia, entidades estatales y organizaciones asociativas de personas con discapacidad tanto en Colombia como en otras partes de la región y del mundo. 
El presente documento tiene como finalidad exponer el contexto normativo, delimitar el contenido y analizar la incidencia en la decisión final de la intervención presentada por PAlls a solicitud de la Corte Constitucional, en los casos con expedientes n. ${ }^{\circ}$ T-3672842 y T-3754187 acumulados, correspondientes a las acciones de tutela instauradas por Luis Antonio Pérez Covos y Marcos Omar Suárez Piragauta contra Coldeportes, las cuales dieron lugar a la sentencia T-287 de 2013, proferida por la Sala Sexta de revisión de la Corte Constitucional.

Así, en primer lugar, se hará un análisis de las diferentes aproximaciones al concepto de discapacidad desarrolladas en varios momentos históricos, y se presentará el marco normativo de dichas conceptualizaciones; acto seguido, se abordará el asunto concreto sobre el cual versó la intervención realizada por PAlls, así como los planteamientos expuestos; luego, se mencionarán los temas y puntos tratados por la Corte en la sentencia que resuelve el caso objeto de revisión; y, finalmente, se hará el análisis de la incidencia de la intervención de PAlls en el pronunciamiento de la Corte.

\section{APROXIMACIONES CONCEPTUALES A LA DISCAPACIDAD Y EVOLUCIÓN DEL MARCO INTERNACIONAL DE LOS DERECHOS HUMANOS SOBRE LAS PERSONAS CON DISCAPACIDAD}

A lo largo de la historia se han desarrollado diferentes modelos de aproximación a la discapacidad, de los cuales es factible identificar tres predominantes por ser los que han orientado el tratamiento dado a la población con discapacidad y determinado los marcos normativos aplicados a esta: el de prescindencia, el rehabilitador y el social ${ }^{3}$.

\section{A. Modelo de prescindencia ${ }^{4}$}

El modelo de prescindencia entiende la discapacidad desde una perspectiva metafísica, esto es, "como un castigo de los dioses, el producto de brujería o de una maldición"5; desconoce la dignidad humana de la persona con discapacidad, y considera legítimo prescindir de ella o relegarla al ostracismo. La respuesta de los sistemas jurídicos bajo este modelo es la eliminación de las personas con discapacidad, la sustracción total de su capacidad jurídica y su segregación y aislamiento social en instituciones destinadas a mantenerlas allí, sin ningún desarrollo de sus potenciales.

Correlativamente, este modelo entiende a las personas con discapacidad como un grupo que no tiene nada que aportar a la sociedad, sea porque al nacer con ella no se les otorgan las oportunidades necesarias para lograr su inclusión en todas las esferas de la vida social, sea porque una vez adquirida se las ve como una carga, como un problema.

PALACIOS, Agustina. El modelo social de la discapacidad: orígenes, caracterización y plasmación en la Convención Internacional sobre los Derechos de las Personas con Discapacidad. España: Ediciones Cinca, 2008.

$4 \quad$ Ibíd., p. 37.

5 CORTE CONSTITUCIONAL. Sentencia T-139 de 2013. M. P.: Luis Ernesto Vargas Silva. 
De acuerdo con lo planteado por Palacios ${ }^{6}$ el modelo de prescindencia puede presentarse de forma eugenésica o como marginación. La primera tiene como elemento común a las dos manifestaciones la terminación de la vida, de forma directa o indirecta, y la segunda, además del elemento común, tiene como fundamento esencial la exclusión de la persona de las oportunidades sociales. Las personas con discapacidad son equiparadas a seres anormales, que dependen "de otros y por tanto son tratadas como objeto de caridad y sujetos de asistencia"7.

\section{B. Modelo de rehabilitación o médico ${ }^{8}$}

Este concibe la discapacidad como la manifestación de diversas condiciones físicas, fisiológicas o psicológicas que alteran la normalidad orgánica de la persona ${ }^{9}$, es decir, la atribuye a una causa científica: la enfermedad. Por consiguiente, respeta la dignidad de las personas con discapacidad y las considera "potencialmente útiles", en la medida en que puedan superar su diagnóstico médico y sean rehabilitadas o "normalizadas". Así, bajo este modelo se busca la prevención de la discapacidad, la recuperación de la persona con discapacidad y su "curación"10. La visión de integración que propugna el modelo rehabilita-

6 PALACIOS, ob. cit., p. 38.

7 CORTE CONSTITUCIONAL. Sentencia C-804 de 2009. M. P.: María Victoria Calle Correa,

$8 \quad$ PALACIOS, ob. cit., p. 66.

9 CORTE CONSTITUCIONAL. Sentencia T-340 de 2010. M. P.: Juan Carlos Henao Pérez.

10 PALACIOS, ob. cit. dor se basa en la noción de normalidad, a la vez que predica la aceptación de las personas con discapacidad y la tolerancia respecto de determinadas necesidades ${ }^{11}$.

La respuesta de los sistemas jurídicos que operan desde este modelo patologiza a las personas con discapacidad, pues las entiende desde el ámbito de la salud y la rehabilitación. Además, otorgan la voz "experta" a los médicos y psiquiatras. Este modelo es aún prevalente en la normativa colombiana, de ahí que los únicos autorizados para certificar que una persona tiene una discapacidad son los médicos, los psiquiatras y las juntas médicas. Sin embargo, poco reconocimiento recibe en nuestro ordenamiento la voz de las personas mismas ${ }^{12}$, en el mejor de los casos los familiares son quienes hablan por ellas.

\section{Modelo social}

El modelo social, por su parte, asocia la discapacidad a la reacción social o a las dificultades de interacción con el entorno, derivadas de esa condición ${ }^{13}$. Así, la discapacidad resulta de la interacción entre las limitaciones funcionales de una persona y las barreras que le impiden el ejercicio pleno de sus derechos y libertades ${ }^{14}$.

11 Ibíd.

12 Ver, por ejemplo, el régimen de capacidad legal en Colombia y la Ley 1306 de 2009 o la Ley 100 de 1993 sobre el régimen de seguridad social.

13 CORTE CONSTITUCIONAL. Sentencia T-109 de 2012. M. P.: María Victoria Calle Correa.

14 PALACIOS, ob. cit. 
Partiendo de lo anterior, este enfoque hace una distinción entre lo que comúnmente se denomina deficiencia y lo que se entiende por discapacidad, para señalar que la noción de persona con discapacidad se basa, más allá de la diversidad funcional, en las limitaciones o restricciones que experimentan y que les impide llevar una vida en sociedad, constituyendo esta una forma de opresión social ${ }^{15}$.

Entonces, la discriminación hacia la población con discapacidad opera en función de los límites, obstáculos, desventajas o restricciones que la sociedad contemporánea les impone en la prestación de los servicios y medios adecuados para asegurarles una inclusión real y efectiva en la sociedad ${ }^{16}$; en otras palabras, a la negación por parte de la sociedad de las condiciones que les permitan acomodar sus necesidades individuales y colectivas dentro de la actividad general que supone la vida económica, social y cultural $^{17}$. Al respecto, Colin Barnes destaca que este modelo no consiste más que en un énfasis en las barreras económicas, medioambientales y culturales que encuentran las personas a las que otros consideran con algún tipo de diversidad funcional ${ }^{18}$.

15 Ibíd.

16 CORTE CONSTITUCIONAL. Sentencia T-139 de 2013. M. P.: Luis Ernesto Vargas Silva. "Esta perspectiva "social", concibe a las personas con discapacidad como un grupo humano con diversidad funcional que debe ser abordado desde el punto de vista de su capacidad humana y no solamente desde su limitación. Como consecuencia, las medidas estatales relativas a estas personas deben orientarse al desarrollo del mayor nivel posible de autonomía y participación en todas las decisiones que los afecten".

17 PALACIOS, ob. cit.

18 BARNES, C. Las teorias de la discapacidad y los orígenes de la opresión de las personas discapacitadas en la sociedad occidental. En:
Por lo anterior, conforme a este modelo las soluciones deben estar encaminadas y dirigidas hacía la sociedad, o teniendo muy presente el contexto social en el cual la persona desarrolla su vida.

La Convención sobre los Derechos de las Personas con Discapacidad (la Convención), adoptada por la Asamblea General de la Naciones Unidas el 13 de diciembre de 2006, consagra la materialización del modelo social como obligación internacional. Así, las personas con discapacidad son plenos sujetos de derechos, plenos ciudadanos y, por tanto, se entiende que tienen todo el potencial para aportar a la comunidad o sociedad a la que pertenecen. Como lo establece el artículo 1 de la Convención, son personas que hacen parte de la diversidad que caracteriza la condición humana, y como tal sus derechos deben ser reconocidos, protegidos y promovidos por el Estado y por la sociedad.

Colombia, mediante la Ley 1346 de 2009 “Por medio de la cual se aprueba la “Convención sobre los Derechos de las Personas con Discapacidad", se adhirió a esta y la ratificó el 11 de mayo de 2011. Con dicha ratificación el Estado colombiano no solo integró al ordenamiento jurídico interno las normas que la Convención prevé, sino que en virtud del artículo 93 de la Constitución Política aquella entró al "conjunto de normas que se utilizan como parámetro para analizar la validez constitucional de las

Discapacidad y Sociedad. L. Barton (comp.). Madrid: Ediciones Morata S. L., 1998. 
leyes" ${ }^{19}$. Es decir, es parte integrante del bloque de constitucionalidad stricto sensu, "el cual obedece a aquellos principios y normas que han sido normativamente integrados a la Constitución por diversas vías y por mandato expreso de la Carta, por lo que entonces tienen rango constitucional" ${ }^{20}$. De esta manera, el Estado adquirió una serie de obligaciones encaminadas a cambiar la concepción de los modelos médico y asistencialista de discapacidad.

\section{Evolución del marco internacional de derechos humanos sobre discapacidad}

En 1976, la Asamblea General de las Naciones Unidas reafirmando la fe en los derechos humanos y las libertades fundamentales, los principios de la paz, la dignidad y el valor de la persona humana y la promoción de la justicia social, según se establece en la Carta de dicha Organización, proclamó a 1981 como el Año Internacional de los Impedidos, con el objetivo de poner en marcha un plan de acción a nivel nacional, regional e internacional que prestara especial atención a la igualdad de oportunidades, la rehabilitación y la prevención de las discapacidades $^{21}$. Dicha proclamación aparejó el

19 CORTE CONSTITUCIONAL. Sentencia C-582 de 1999. M. P.: Alejandro Martínez Caballero.

20 CORTE CONSTITUCIONAL. Sentencia C-582 de 1999. M. P.: Alejandro Martínez Caballero. En oposición a la noción lato sensu del bloque de constitucionalidad referida a aquellas disposiciones que "tienen un rango normativo superior a las leyes ordinarias", que sin tener rango constitucional sirven como criterios de interpretación para la creación legal y para el control constitucional.

21 ORGANIZACIÓN DE NACIONES UNIDAS. La ONU y las personas con discapacidad: historia de la discapacidad y Naciones Unidas. [Consultado 7 de noviembre de 2013]. Disponible en: <http://www. un.org/spanish/esa/social/disabled/disiydp.htm> reconocimiento internacional de los derechos de las personas con discapacidad desde la perspectiva de los derechos humanos, esto es, desde el reconocimiento de la dignidad intrínseca y de los derechos iguales e inalienables de todas las personas, así como de los derechos fundamentales del hombre y el valor de la persona humana.

En ese sentido, reafirmó la necesidad de las personas con discapacidad de contar con un conjunto de servicios que les permita gozar de una situación que los habilite para desempeñarse como ciudadanos activos, participar plenamente en la vida y el desarrollo de sus respectivas sociedades, disfrutar de unas condiciones de vida iguales a las de otros ciudadanos y a compartir las condiciones mejoradas que se derivan del desarrollo socioeconómico ${ }^{22}$.

Lograr lo anterior implicaba incrementar la sensibilización pública, lograr un mayor entendimiento y aceptación de las personas que tienen alguna discapacidad, animar a dichas personas a formar organizaciones a través de las cuales pudieran expresar sus opiniones y promover medidas para mejorar su situación. Para ello, el 3 de diciembre de 1982, mediante resolución 37/52, la Asamblea General de las Naciones Unidas aprobó el Programa de Acción Mundial para los Impedidos (el Programa), cuyo objetivo consistía en promover medidas eficaces para la prevención de la incapacidad, la rehabilitación y la realización de los objetivos de "participación

\footnotetext{
22 ORGANIZACIÓN DE NACIONES UNIDAS. Asamblea General. Resolución 31/123 de 16 de diciembre de 1976.
} 
plena" de los impedidos en la vida social y el desarrollo, y de "igualdad" 23 .

Unos años más adelante, luego de la Reunión Mundial de Expertos celebrada en el año 1987, en Estocolmo, en la cual se examinó la marcha en la ejecución del Programa, se sugirió la necesidad de elaborar una doctrina rectora que indicase las prioridades de acción en el futuro, basándose en los derechos de las personas con discapacidad. Después de la presentación por parte de Italia del primer esbozo de la Convención internacional sobre la eliminación de todas las formas de discriminación contra las personas con discapacidad, sin que se llegara a ningún acuerdo con la comunidad internacional acerca de su conveniencia, finalmente se autorizó a la Comisión de Desarrollo Social a conformar un grupo especial de expertos para que elaborara unas normas uniformes sobre la igualdad de oportunidades para niños, jóvenes y adultos con discapacidad, con el fin de examinarlas y presentarlas a la Asamblea General en el año 1993.

Efectivamente, el 20 de diciembre de 1993 la Asamblea General, mediante resolución 48/96, aprobó las Normas Uniformes sobre la igualdad de oportunidades para las personas con discapacidad, cimentadas política y moralmente en la experiencia adquirida en el Decenio de las Naciones Unidas para los Impedidos, la Carta Internacional de Derechos Humanos ${ }^{24}$, la Con-

23 ORGANIZACIÓN DE NACIONES UNIDAS. Programa de acción mundial para los impedidos. [Consultado 8 de noviembre de 2013]. Disponible en: <http://www.un.org/esa/socdev/enable/diswps01.htm\#A>

24 Comprende la Declaración Universal de los Derechos Humanos, el Pacto Internacional de Derechos Económicos, Sociales y Culturales, y el Pacto Internacional de Derechos Civiles y Políticos. vención sobre los Derechos del Niño y la Convención sobre la eliminación de todas las formas de discriminación contra la mujer, así como en el Programa de Acción Mundial para los Impedidos. Si bien estas normas llevan implícito el compromiso de los Estados de adoptar medidas que conduzcan a la igualdad de oportunidades, y señalan principios de responsabilidad, acción y cooperación, no tienen carácter vinculante ${ }^{25}$, por lo que no son de obligatorio cumplimiento. Su principal finalidad es lograr que los niños, jóvenes y adultos que tengan alguna discapacidad, en su calidad de ciudadanos pertenecientes a una sociedad puedan tener los mismos derechos y obligaciones que los demás ${ }^{26}$.

Sin embargo, las personas con discapacidad continúan siendo consideradas sujetos de protección social que despiertan lástima más que respeto, y carecen de las oportunidades que tiene el resto de la población por los diversos obstáculos que les impiden recibir educación, hacer parte de un mercado laboral, acceder a la información, obtener el adecuado cuidado médico y

25 Si bien seis de las principales convenciones de Naciones Unidas sobre derechos humanos abordan cuestiones relacionadas con la discapacidad, sus disposiciones no se enfocan en este tema en particular. Asimismo, los instrumentos que se pronuncian a favor de los derechos de los discapacitados no son vinculantes. En consecuencia, los discapacitados enfrentan el dilema de ser legalmente "invisibles" para sus sociedades e incluso para la comunidad internacional. Durante mucho tiempo, la mayoría de las inquietudes de las personas con discapacidad han sido tratadas como parte de un enfoque de asistencia social. ORGANIZACIÓN DE NACIONES UNIDAS. 10 historias que el mundo debería conocer mejor. Las personas con discapacidad: un tratado que busca abrir el camino hacia la igualdad. [Consultado 6 de noviembre de 2013]. Disponible en <http://www.un.org/spanish/events/tenstories/2006/story.asp?storylD=1000>

26 PROGRAMA DE LAS NACIONES UNIDAS PARA EL DESARROLLO. Compendio de Legislación sobre Discapacidad: Marco Internacional, Interamericano y de América Latina. México. [Consultado el 10 de noviembre de 2013]. Disponible en <http://conadis.salud.gob.mx/descargas/pdf/CLSDtomo1.pdf> 
sanitario, desplazarse e integrarse en la sociedad y ser aceptados. De acuerdo con el Informe mundial sobre la discapacidad, producido por la Organización Mundial de la Salud y el Grupo del Banco Mundial:

En todo el mundo, las personas con discapacidad tienen peores resultados sanitarios, peores resultados académicos, una menor participación económica y unas tasas de pobreza más altas que las personas sin discapacidad. En parte, ello es consecuencia de los obstáculos que entorpecen el acceso de las personas con discapacidad a servicios que muchos de nosotros consideramos obvios, en particular la salud, la educación, el empleo, el transporte, o la información. Esas dificultades se exacerban en las comunidades menos favorecidas ${ }^{27}$.

Por ello, la Comisión de Derechos Humanos de las Naciones Unidas reconoció que era responsabilidad de la comunidad internacional generar un marco legal para proteger los derechos de las personas con discapacidad ${ }^{28}$, esto es, un marco jurídico vinculante que estableciera obligaciones para los Estados que lo adoptaran y ratificaran, así como mecanismos de control y, por ende, sanciones frente al incumplimiento. Con la ratificación, cada país acepta las obligaciones jurídicas del tratado y se compromete a adoptar toda la normativa necesaria y adecuada para hacerlas cumplir.

27 ORGANIZACIÓN MUNDIAL DE LA SALUD Y BANCO MUNDIAL. Informe mundial sobre la discapacidad. [Consultado el 7 de noviembre de 2013]. Disponible en <http://www.who.int/disabilities/world_report/2011/summary_es.pdf>

28 ORGANIZACIÓN DE LAS NACIONES UNIDAS. Convención sobre los derechos de las personas con discapacidad. [Consultado el 10 de noviembre de 2013]. Disponible en <http://www.un.org/spanish/disabilities/convention/qanda.html>
En ese orden de ideas, la comunidad internacional, motivada por el Estado de México, con la intención de proteger y promover los derechos humanos de las personas con discapacidad y garantizarles las mismas oportunidades de la población en general, decidió el 19 de diciembre de 2001, en las Naciones Unidas, conformar un Comité especial Ad hoc, para iniciar el proceso dirigido a la consecución de una convención internacional amplia e integral para proteger y promover los derechos de las personas con discapacidad $^{29}$.

Después de ocho periodos de sesiones en las que se debatieron aspectos como la necesidad o no de un nuevo tratado, el instrumento internacional a adoptar, la exigibilidad de los derechos, las medidas para garantizarlos, las obligaciones y sanciones, el 25 de agosto de 2006 el Comité especial adoptó el proyecto de convención, incluido un protocolo facultativo.

Así, el 13 de diciembre de 2006 se aprobó en la Asamblea General de la onu la Convención internacional sobre los derechos de las personas con discapacidad y el Protocolo consultivo de dicha convención, y el 3 de mayo de 2008 entró en vigor. La participación de las personas con discapacidad en el proceso de redacción de la Convención fue fundamental, lo que quedó plasmado en el espíritu y en el texto del articulado ${ }^{30}$.

OBSERVATORIO ESTATAL DE LA DISCAPACIDAD. La Convención Internacional sobre los Derechos de las Personas con Discapacidad y su aplicación en España. Informe. [Consultado el 7 de noviembre de 2013]. Disponible en <http://www.observatoriodeladiscapacidad.es/ sites/default/files/io/02_capitulo2.pdf> 
El proceso de negociación fue también enriquecedor para los actores que intervinieron, pues contribuyó a incrementar la conciencia respecto del enfoque de derechos en el ámbito de la discapacidad, además de reforzar las relaciones entre las organizaciones no gubernamentales y cada uno de los gobiernos. La participación de las asociaciones de personas con discapacidad jugó un rol definitivo en las negociaciones.

\section{EL CASO CONCRETO, INTERVENCIÓN CIUDADANA Y DECISIÓN DE LA CORTE}

\section{A. Acciones de tutela presentadas}

Mediante auto de fecha 15 de abril de 2013, el magistrado sustanciador Nilson Pinilla Pinilla, de la Sala Sexta de Revisión de la Corte Constitucional, invitó a PAlls para que se pronunciara, de manera acumulada, sobre las acciones de tutela interpuestas por Luis Antonio Pérez Covos (expediente T-3672842, del Juzgado Octavo Penal del Circuito de Bogotá) y Marcos Omar Suárez Piragauta (expediente T-3754187, del Juzgado Segundo Promiscuo de Familia de Sogamoso), contra el Departamento del Deporte la Recreación, la Actividad Física y el Aprovechamiento del tiempo libre (Coldeportes).

El asunto objeto de revisión y análisis eran los hechos que a continuación se plantean:

1. Los accionantes son deportistas con discapacidad física. Luis Antonio Pérez Covos tiene cuadriplejia, practica tiro deportivo y pertenece a la liga de deportes para personas con limitaciones físicas de Bogotá, Lidesports. Por su parte, Marcos Omar Suárez Piragauta, practica natación y pertenece a la liga de deportes en silla de ruedas de Boyacá, Lidesbo. Los dos han representado al país en eventos nacionales e internacionales.

2. Los deportistas fueron inscritos por sus respectivas ligas para participar en la III versión de los Juegos Paralímpicos Nacionales Carlos Lleras Restrepo, los cuales tuvieron lugar en la ciudad de Cúcuta en el año 2012.

3. Coldeportes, mediante resolución n. ${ }^{\circ} 743$ de julio 3 de 2012, declaró la no realización, entre otras, de las pruebas de natación y de tiro, debido a que no se presentó el número mínimo exigido de tres competidores de tres departamentos diferentes. para llevar a cabo una competencia específica en deportes individuales.

4. Los accionantes presentaron acción de tutela contra ColdePORTES, para que les fueran amparados sus derechos fundamentales a una vida digna, a la recreación, al deporte y a la igualdad.

El juzgado 31 Penal Municipal de Bogotá, quien conocía del expediente T-3672842, en fallo de julio 23 de 2012 declaró improcedente el amparo, pues la no participación del deportista Luis Antonio "obedece únicamente al estricto cumplimiento de las resoluciones en cita, las cuales hacen alusión a la logística y al desarrollo de los III Juegos Paranacionales 2012" y no a un acto de discriminación, dado que las reglas exigidas para la inclusión de determinadas disciplinas deportivas, son exigencias que se extienden a todas las disciplinas. 
Dicho fallo fue impugnado el 13 de agosto de 2012, por considerar el actor que la exclusión de los juegos le ocasiona "un detrimento moral y económico" porque pierde "el subsidio económico como deportista con el agravante que soy una persona en condición de gran discapacidad (cuadripléjico), y las oportunidades como ésta no se presentan sino cada cuatro años".

El juzgado 8 Penal del Circuito de Bogotá, actuando como juez de segunda instancia, en sentencia de septiembre 24 de 2012 confirmó la decisión del a quo, al considerar que no se configuraba un perjuicio irremediable para el accionante, "pues a pesar de no haberse incluido esta prueba dentro de los III JUEgos PARANACIONALES 2012, por no reunir los requisitos establecidos para ello, no imposibilita al accionante para que siga practicando su disciplina y participe en cualquier otro evento en el que la prueba se encuentre prevista" 31 .

Por su parte, el juzgado Segundo Promiscuo de Familia de Sogamoso, con referencia al expediente T-3754184, en fallo de octubre 5 de 2012 emitió sentencia única de instancia en la que negó la tutela al deportista Marcos Omar, al estimar que "se tomó esta decisión porque no existe el número necesario de participantes, respecto de las regiones, departamentos o ligas, que como mínimo deben ser tres para la competencia" 32 .

31 CORTE CONSTITUCIONAL. Sentencia T-287 de 2013. M. P.: Nilson Pinilla Pinilla.

32 Ibíd.

\section{B. Intervención ciudadana}

PAlls realizó la intervención planteando tres postulados, que en la situación concreta inciden en la vulneración de derechos fundamentales y desconocen la Convención sobre los Derechos de las Personas con Discapacidad ${ }^{33}$, a saber:

1. El artículo 32 de la Carta Deportiva Fundamental de los III Juegos Paralímpicos Nacionales "Carlos Lleras Restrepo" constituye una barrera para el ejercicio de los derechos al deporte, al libre desarrollo de la personalidad y a la igualdad de los accionantes, de cara a la Convención sobre los Derechos de las Personas con Discapacidad.

2. Las autoridades encargadas de promover la participación en el deporte de las personas con discapacidad, no han implementado las medidas pertinentes y conducentes para dicho fin, por lo que las ha puesto en un estado de desprotección sistemática.

3. La aplicación del artículo en cuestión vulnera derechos fundamentales de las personas con discapacidad, pues se materializa en un contexto en el que no existen acciones orientadas a la inclusión social.

Frente al primer aspecto, se consideró que la Resolución 00309 del 3 de abril de 2012 o Carta Deportiva Fundamental de los III Juegos Paralímpicos Nacionales 2012 "Carlos Lleras Restrepo", la cual instituye una reglamentación

33

ORGANIZACIÓN DE LAS NACIONES UNIDAS. ASAMBLEA GENERAL. Convención sobre los derechos de las personas con discapacidad. Nueva York, 13 de diciembre de 2006. UNTS. Vol. 2515, p. 3. Ratificada por Colombia el 10 de mayo de 2011. Incorporada mediante Ley 1346 de 2009 
que establece el número mínimo de ligas deportivas que deben inscribirse oficialmente para la realización de dicho evento, y específicamente el artículo 32 que dispone que el número mínimo de deportistas que deben inscribirse para que un deporte individual pueda realizarse sea al menos 3 , siempre y cuando los deportistas pertenezcan a departamentos diferentes, constituye un límite normativo para el ejercicio de los derechos al deporte, al libre desarrollo de la personalidad y a la igualdad de Luis Antonio Pérez Covos y Marco Omar Suárez Piragauta.

Lo anterior, en términos de la Convención sobre los Derechos de las Personas con Discapacidad, según la cual "la discapacidad es un concepto que evoluciona y que resulta de la interacción entre las personas con deficiencias y las barreras debidas a la actitud y al entorno que evitan su participación plena y efectiva en la sociedad, en igualdad de condiciones con las demás".

Se consideró al respecto: primero, que la mencionada Resolución al establecer un número mínimo de deportistas inscritos de diferente departamento para que un deporte individual pueda realizarse, no tuvo en cuenta que, materialmente, las personas con discapacidad son un grupo minoritario y que ha sido una población históricamente discriminada, con acceso muy precario a las prácticas deportivas. Entonces, si se reconoce que en Colombia existen menos personas con discapacidad que sin discapacidad, que socialmente las personas con discapacidad han sido discriminadas, que no han tenido las mismas oportunidades y no han estado en igualdad de condiciones con los demás (cam- bio que marca la Convención), el artículo 32 es un obstáculo para su integración, rehabilitación y participación en la sociedad, en términos de la sentencia T-105 de 2009. Esto, por cuanto desconoce la condición de sujetos de especial protección constitucional de las personas con discapacidad, e impone a quienes practican el deporte y quieren participar en las pruebas individuales una carga desproporcionada. De esta manera, no solo desatiende la obligación del Estado de detenerse en las diferencias que de hecho existen entre las personas, sino el compromiso frente al diseño y ejecución de políticas destinadas a la superación de barreras existentes para quienes por su discapacidad y vulnerabilidad no logran realmente integrarse en la vida social, política, económica o cultural, en condiciones de igualdad ${ }^{34}$.

Segundo, a lo anterior se suma el hecho de que las instituciones involucradas en el desarrollo de medidas conducentes a incentivar y fomentar la participación de las personas con limitaciones físicas no solo en actividades recreativas y de aprovechamiento del tiempo libre, sino también de alta competencia, o no han adelantado dichas políticas o estas no han tenido el impacto esperado; prueba de ello es la falta de participantes de distintos departamentos en las competencias en cuestión.

La carencia de este presupuesto pone en un estado de desprotección sistemática a las personas con discapacidad, pues en todos los

34 CORTE CONSTITUCIONAL. Sentencia T-810 de 2011. M. P.: Mauricio González Cuervo. 
casos las posibilidades de que no se cumplan los requisitos de competitividad son muy altas dado el bajo número de participantes en todas las disciplinas.

Ahora bien, en lo atinente al segundo postulado la intervención se refirió a la incidencia de la Resolución en el derecho al libre desarrollo de la personalidad de los accionantes. En primer lugar, se reiteró que la Resolución, concebida bajo el ideal que las instituciones encargadas incentivan y fomentan de manera real y efectiva el deporte de alto rendimiento en las personas con discapacidad, es una barrera u obstáculo para el desarrollo del proyecto de vida de estas, más cuando dicho presupuesto no es materialmente efectivo. Además, no contribuye a la representación del país en escenarios deportivos internacionales.

Por otra parte, destacó la importancia del deporte como recreación, y la función esencial que esta cumple en la consecución del libre desarroIlo de la personalidad dentro de un marco participativo-creativo, en el cual el individuo revela su dignidad ante sí mismo y ante la sociedad ${ }^{35}$. La recreación es considerada una necesidad fundamental del ser humano, que estimula su capacidad de ascenso, y es una actividad necesaria tanto para su desarrollo individual y social como para su evolución. En ese sentido, el deporte está íntimamente ligado al derecho al libre desarrollo de la personalidad, el cual implica el reconocimiento de la aptitud física y moral

35 CORTE CONSTITUCIONAL. Sentencia C-625 de 1996. M. P.: Hernando Herrera Vergara. que tienen todas las personas a realizarse individual y autónomamente, sin imposiciones o forzamientos de ninguna clase y sin controles injustificados o impedimentos por parte de los demás, incluido el Estado, a menos de que exista una obligación legal o contractual legítima, un deber social o cuando las respectivas acciones atenten contra los derechos de los demás ${ }^{36}$.

Teniendo en cuenta lo precedente, a juicio de PAlls, el artículo 33 de la Carta Deportiva Fundamental de los III Juegos Paralímpicos Nacionales, es decir, la exigencia de mínimo tres participantes de distintos departamentos para la realización de las competencias individuales, constituye una medida injustificada, si se tiene en cuenta: i. La condición de sujetos de especial protección constitucional de las personas con discapacidad, en general, y de los accionantes, en particular; ii. Los accionantes son parte de un grupo históricamente discriminado; iii. La carencia de incentivos y fomentos idóneos para la participación en competencias de alto rendimiento de personas con discapacidad; y iv. La intromisión en el derecho de autodeterminación que da la posibilidad de implementar un proyecto de vida individual con objetivos que cada individuo pueda diseñar, como el deporte y la participación en competencias de alto rendimiento, en el caso concreto.

Todo lo anterior, debido a que existen otras alternativas menos lesivas, que no comprometen el ejercicio de los derechos a la igualdad y al libre

36 CORTE CONSTITUCIONAL. Sentencia T-977 de 2012. M. P.: Alexei Julio Estrada. 
desarrollo de la personalidad de los deportistas nacionales que desean participar en competencias internacionales en las que haya más competidores en la misma actividad y con la misma discapacidad. Por ejemplo, establecer competencias individuales en las que los deportistas compitan con el objetivo principal de medir su propio rendimiento frente a marcas olímpicas establecidas internacionalmente.

Finalmente, el concepto de pAlls reitera que la aplicación de una Resolución en un contexto para el cual no fue concebida pone un límite desconocedor de la especial protección constitucional de que gozan las personas con discapacidad, y en esa medida a la vida deportiva del jugador y a su participación en eventos deportivos internacionales, más aún si se tiene en cuenta que dichos juegos son cada cuatro años. Con esto, se vulneran los derechos al deporte, a la igualdad, al libre desarrollo de la personalidad e incluso al mínimo vital, cuando el incentivo económico que los deportistas reciben por su participación constituye su única fuente de ingresos.

Se concluye indicando que, por las razones antes descritas, se desconoce lo preceptuado en la Constitución Política, artículos 13 y 16. Así mismo, se incumplen las obligaciones internacionales adquiridas por el artículo 93 superior, referido al bloque de constitucionalidad, tal como las establecidas en la Convención sobre los derechos de las personas con discapacidad.

\section{Sentencia T- 287 de 2013}

La sentencia fue proferida el 20 de mayo de 2013 por la Sala Sexta de Revisión de la Corte Constitucional, integrada por los magistrados Nilson Pinilla, Jorge Ignacio Pretelt Chaljub y Alberto Rojas Ríos. En ella aparece un recuento de los hechos en donde se menciona la respuesta de Coldeportes; los documentos relevantes que reposan en el expediente; las providencias objeto de análisis; se citan las pruebas ordenadas por el magistrado sustanciador $y$, finalmente, las consideraciones que llevaron a la decisión.

El recuento de los hechos se hizo en bloque y atiende a los ya mencionados en el aparte precedente. Ahora, frente a la respuesta de Coldeportes, se resalta que el director de dicha entidad pidió negar el amparo de los derechos alegados por los accionantes, con base en tres argumentos, a saber:

1. En ambos casos, para "que exista competencia deportiva debe existir un enfrentamiento o contienda de varios sujetos respecto de algo";

2. La determinación de no realizar las pruebas se debió a que no se reunieron los requisitos establecidos en el artículo 33 de la Resolución 000364 de abril 26 de 2012, el cual establece que para realizar una competencia específica en deportes individuales es necesario contar mínimo con tres (3) competidores de tres (3) departamentos diferentes.

3. El hecho de no haber sido incluidos en los III Juegos Paranacionales 2012, no imposibilita a los accionantes para que sigan practicando su disciplina y participen en cualquier otro evento nacional. 
Finalmente, el funcionario concluyó diciendo que en todo evento deportivo se deben establecer una serie de criterios de organización, participación y competencia para el buen desarrollo de este, pero en ningún momento se busca limitar el acceso de la comunidad, ni mucho menos vulnerar su derecho a la práctica del deporte, al libre desarrollo de la personalidad y a la igualdad.

Seguido, la Corte hizo el recuento de los fallos objeto de revisión, en los términos en que se expusieron al comienzo del numeral II: El caso concreto. A su vez, se refirió a las pruebas ordenadas por el magistrado sustanciador mediante auto de fecha 15 de abril de 2013, esto es, a las intervenciones de las autoridades en el tema ${ }^{37}$ a quienes la Corte invitó a pronunciarse sobre el asunto de referencia, a saber:

El director jurídico del Ministerio de Salud y Protección Social, quien respondió en representación de su entidad, se refirió a la construcción de la nueva política pública nacional en materia de discapacidad y la participación que en dicho proceso han tenido diversos actores, en especial Coldeportes, quien ha aportado desde sus necesidades con respecto al deporte paralímpico y ha formulado estrategias para fomentar la actividad física y la recreación a través de programas y proyectos.

La coordinadora académica de la Maestría en Discapacidad e Inclusión Social de la Facultad de Medicina de la Universidad Nacional se pronunció respecto a la adopción de ajustes razo- nables, los cuales hubieran podido mantener la competencia deportiva en el caso en cuestión. Por ejemplo, "permitir que el deportista compita contra su propia marca, registro o récord para su categoría” o "considerar opciones de deporte de exhibición"38.

En cuanto a la intervención de PAlls la Corte destacó lo siguiente:

Por su parte, el Programa de Acción por la Igualdad y la Inclusión Social (PAIIS) mediante escrito de abril 30 de 2013 señaló que: "la omisión de COLDEPORTES de ofrecer un trato especial a los accionantes, personas con debilidad manifiesta, en la circunstancia en que se decreta la no realización de competencias por no contar con al menos tres competidores de distintos departamentos, tal como lo establece la Carta Fundamental de los III Juegos Paralímpicos Nacionales, resulta vulneratoria del derecho a la igualdad, toda vez que no reconoce la situación de desventaja en que se encuentran los recurrentes, debido a su propia condición y, a las medidas impertinentes o no óptimas de las instituciones encargadas de incentivar el deporte en personas con discapacidad."

Indicó que COLDEPORTES no solo debió permitir la participación de los accionantes en las competencias de los III Juegos Paralímpicos Nacionales, siendo que dicha normativa constituye una barrera para las personas con discapacidad para acceder a los derechos a la igualdad y al deporte, sino que también debió buscar e implementar los mecanismos propicios para incentivar y fomentar el deporte de alto rendimiento.

37 La Corporación Discapacidad Colombia también fue invitada por la Corte a pronunciarse con carácter de autoridad en el tema. 
Agregó que "aún, cuando coldePORTES hubiera agotado todos los instrumentos conducentes para ello, y se hubiera presentado la misma circunstancia de no existir competidores de distintos departamentos impidiendo la realización de las competencias individuales, no puede existir una resolución, concebida bajo el ideal de que las instituciones encargadas incentivan y fomentan de manera real y efectiva el deporte de alto rendimiento en las personas con discapacidad, convertirse en una barrera u obstáculo para el desarrollo del proyecto de vida de una persona, además de no contribuir a la representación del país en escenarios deportivos internacionales".

Así concluyó que el mínimo de participantes de distintos departamentos exigido para la realización de las competencias individuales constituye para los accionantes una medida injustificada, si se tiene en cuenta su situación de especial protección constitucional y la carencia de incentivos y fomentos idóneos para la participación en competencias de alto rendimiento de personas con discapacidad.

Una vez observado lo anterior, la Corte procedió a hacer sus consideraciones. En primer lugar, definió el asunto objeto de análisis en los siguientes términos: ¿Ha vulnerado Coldeportes los derechos fundamentales a una vida digna, a la recreación, al deporte y a la igualdad de los accionantes, al no permitirles participar en los Juegos Paralímpicos Nacionales, debido a que para llevar a cabo una competencia específica en los deportes individuales que practican, es necesario como mínimo tres competidores de tres departamentos diferentes y en sus casos, no se presentó el número mínimo exigido?
Partiendo de dicho problema jurídico se refirió a la eventual improcedencia de la tutela por carencia de objeto y al asunto de las personas en situación de discapacidad como sujetos de especial protección constitucional, para decidir los dos casos concretos.

En cuanto a la improcedencia de la acción de tutela por carencia actual de objeto, estableció que, tal como se ha reiterado en varias ocasiones, si la satisfacción del derecho o el menoscabo se presentan durante el trámite de las instancias o en sede de revisión surge la carencia actual de objeto, que hace ineficaz la tutela, al existir un hecho superado si se restableció la garantía invocada, o un daño consumado al no quedar opción de restablecimiento o defensa ${ }^{39}$. Sin embargo, reiterando la posición unificada, se debe emitir un pronunciamiento de fondo cuando se percibe la existencia de un daño consumado, aun en aquellos casos en los que solo resulta posible emitir órdenes de prevención a las autoridades concernidas en el asunto objeto de estudio; por esto, la Sala emitió pronunciamiento de fondo, postergando la determinación de un posible daño al análisis del caso concreto.

Ahora bien, en lo que respecta a las personas con discapacidad como sujetos de especial protección constitucional, y específicamente al alcance de la protección que se desprende de los instrumentos internacionales, la Corte dejó en firme que las personas con discapacidad son sujetos de especial protección por mandato expreso de

39 CORTE CONSTITUCIONAL. Sentencia T-083 de febrero 11 de 2010. M. P.: Humberto Antonio Sierra Porto. 
la Constitución Política, artículos 13 y $47^{40}$. Además, reiteró que existe un marco jurídico internacional para estructurar una dogmática que esclarezca las obligaciones adquiridas por el Estado en el ámbito internacional, sobre el alcance de la protección de las personas con discapacidad.

Así, se refirió a las Normas uniformes sobre la igualdad de oportunidades para las personas con discapacidad; a la Convención Interamericana para la Eliminación de Todas las Formas de Discriminación contra las Personas con Discapacidad, a la Observación General n. 5 del Comité de Derechos Económicos, Sociales y Culturales de las Naciones Unidas, en la que se interpretan las obligaciones frente a la población con discapacidad derivadas del Pacto Internacional de Derechos Económicos, Sociales y Culturales (PIDESC) y al Protocolo de San Salvador sobre derechos económicos, sociales y culturales, como referentes para acceder a criterios y parámetros técnicos para determinar cuándo se considera que una persona se encuentra en situación de discapacidad. También para reconocer la especial relevancia del principio de no discriminación en la materia, además del deber del Estado de adoptar medidas positivas para lograr que estas personas gocen plenamente de todos los derechos humanos.

40 CORTE CONSTITUCIONAL. Sentencia T-287 de 2013. M. P.: Nilson Pinilla Pinilla. Esta corporación ha establecido en jurisprudencia reiterada y uniforme que las personas con discapacidad son sujetos de especial protección constitucional, como consecuencia de los mandatos de igualdad ante la ley, prohibición de discriminación, y promoción y protección de grupos tradicionalmente discriminados o personas en condición de debilidad manifiesta (artículo 13 Superior), y de la obligación del Estado de propiciar la reintegración y rehabilitación de las personas en condición de discapacidad (artículo 47 Superior).
Mencionó con especial énfasis la Convención sobre derechos de las Personas con Discapacidad, en lo atinente a su propósito; principios de accesibilidad universal; diseño universal de productos, entornos, programas y servicios para que puedan ser utilizados por todas las personas, sin necesidad de adaptación ni diseño especializado, y ajustes razonables; y a las obligaciones del Estado.

En este último punto, es decir, en las obligaciones del Estado de cara a la Convención sobre los Derechos de las Personas con Discapacidad, la Corte destacó aquellas consistentes en "Tomar todas las medidas pertinentes, incluidas medidas legislativas, para modificar o derogar leyes, reglamentos, costumbres y prácticas existentes que constituyan discriminación contra las personas con discapacidad; y c) Tener en cuenta, en todas las políticas y todos los programas, la protección y promoción de los derechos humanos de las personas con discapacidad" (artículo 4º); la prohibición de discriminación, en el caso de las personas con discapacidad comporta la obligación de efectuar ajustes razonables (artículo $\left.5^{\circ}\right)$; el principio de toma de conciencia obliga al Estado a adoptar medidas efectivas para luchar contra estereotipos, prejuicios y prácticas nocivas contra la población en situación de discapacidad, y a promover la valoración social de las "capacidades y aportaciones de las personas con discapacidad" (artículo $8^{\circ}$ ). En materia de deporte y recreación, se menciona lo siguiente (artículo 30 numeral $5^{\circ}$ ):

A fin de que las personas con discapacidad puedan participar en igualdad de condiciones con 
las demás en actividades recreativas, de esparcimiento y deportivas, los Estados Partes adoptarán las medidas pertinentes para: a) Alentar y promover la participación, en la mayor medida posible, de las personas con discapacidad en las actividades deportivas generales a todos los niveles; b) Asegurar que las personas con discapacidad tengan la oportunidad de organizar y desarrollar actividades deportivas y recreativas específicas para dichas personas y de participar en dichas actividades $y$, a ese fin, alentar a que se les ofrezca, en igualdad de condiciones con las demás, instrucción, formación y recursos adecuados; c) Asegurar que las personas con discapacidad tengan acceso a instalaciones deportivas, recreativas y turísticas.

A lo anterior, agregó la revisión de constitucionalidad $^{41}$ de la Ley Estatutaria 1618 de 2013 “por medio de la cual se establecen disposiciones para garantizar el pleno ejercicio de los derechos de las personas con discapacidad", que en su artículo $18^{42}$ dispone lo referente al derecho

41 CORTE CONSTITUCIONAL. Sentencia C-765 de octubre 3 de 2012. M. P.: Nilson Pinilla Pinilla.

42 Artículo 18, Ley Estatutaria 1618 de 2013. "DERECHO A LA RECREACIÓN Y DEPORTE. EI Estado garantizará el derecho a la participación en la vida cultural, las actividades recreativas, el esparcimiento y el deporte de las personas con discapacidad, de conformidad con el artículo 30 de la Ley 1346 de 2009. Para garantizar el ejercicio efectivo del derecho a la recreación y el deporte, el Ministerio de Cultura, Ministerio de Educación y Coldeportes junto con los actores del Sistema Nacional del Deporte (Comité Paralímpico y Olímpico Colombiano, federaciones, ligas paralímpicas, organizaciones de y para personas con discapacidad, los Entes territoriales del deporte y la recreación), formularán e implementarán programas inclusivos y equitativos para las personas con discapacidad y los lineamientos para la práctica de educación física, recreación, actividad física y deporte para la población con discapacidad. Además, se fortalecerá el ámbito administrativo y técnico para lo cual adoptarán las siguientes medidas:

1. Fortalecer el deporte de las personas con discapacidad, incluyendo el deporte paralímpico, garantizando áreas de entrenamiento, juzgamiento, apoyo médico y terapéutico, así como la clasificación funcional por parte del Sistema Nacional del Deporte.

2. Fomentar la práctica del Deporte Social Comunitario como un proceso de inclusión social encaminado a potencializar las capacida- a la recreación y deporte.

Todo lo anterior, para concluir que en materia de especial protección constitucional de personas con discapacidad, por un lado, estas efectivamente tienen tal condición, y por otro, que las medidas destinadas a fomentar la participación en el deporte y la recreación por parte de dichas personas deben (i) garantizar la participación de los interesados en el diseño y estructuración

des y habilidades de acuerdo al ciclo vital de las personas con discapacidad.

3. Apoyar actividades deportivas de calidad para las personas con discapacidad, sin exclusión alguna de los escenarios deportivos y recreativos en lo relacionado a la accesibilidad física, de información y comunicación.

4. Suministrar el soporte para el desarrollo, importación o intercambio de implementos deportivos específicos por tipo de discapacidad según estudios técnicos sobre las necesidades de las personas con discapacidad, en concordancia con las disciplinas deportivas y sin el cobro de los aranceles de importación.

5. Garantizar la inclusión de las personas con discapacidad en la recreación a través de la organización y certificación de las entidades de recreación, Registro Único Nacional RUN avalado por Coldeportes Nacional. Inclusión en los currículos de los diferentes niveles de estudio sobre recreación en personas con discapacidad y la acreditación de profesionales.

6. Promover la actividad física de las personas con discapacidad a través de inclusión en los currículos de los diferentes niveles de estudio, sobre actividad física para esta población, con la acreditación de profesionales y generación de estudios complementarios con énfasis en actividad física, educación física adaptada o incluyente y deporte paralímpico.

7. Efectuar las medidas necesarias que garanticen la recreación para las personas con discapacidad, en condiciones de inclusión.

8. Promover ajustes y abrir espacios de formación deportiva, en condiciones de igualdad y en entornos inclusivos para personas con discapacidad.

9. Los incentivos a los deportistas con discapacidad han de ser los mismos que para los deportistas convencionales a nivel municipal, departamental y nacional. Esto implica un programa de deportista apoyado, incentivo a medallistas nacionales e internacionales y apoyo a las futuras glorias del deporte de personas con discapacidad.

10. Motivar las organizaciones de discapacidad cognitiva, sensorial y física, para que sean parte activa de la vida cultural, recreativa y deportiva." 
de los programas; (ii) tomar en cuenta los principios de diseño universal, accesibilidad para todos y todas, y ajustes razonables; (iii) promover la toma de conciencia y (iv) no construirse mediante esquemas discriminatorios ${ }^{43}$.

Acto seguido la Corte se ocupó del análisis de una posible vulneración de derechos en el caso concreto. Al respecto concluyó que el hecho de que Coldeportes no haya permitido participar a los accionantes en los Juegos Paralímpicos Nacionales, debido a que para llevar a cabo una competencia específica en los deportes especiales que practican es necesario como mínimo tres competidores de tres departamentos diferentes, y en el caso de los actores no se presentó el número mínimo exigido, no constituye una vulneración de derechos fundamentales. Argumentó que si bien las personas con discapacidad son sujetos de especial protección constitucional, y el Estado tiene la obligación de tomar todas las medidas necesarias, incluidas las legislativas, para modificar o derogar leyes, reglamentos, costumbres y prácticas existentes que constituyan discriminación contra las personas con discapacidad; así como efectuar ajustes razonables y avanzar en la igualdad de oportunidades, entre otras; las normas deportivas tendientes a determinar quiénes pueden participar e inscribirse en un campeonato, así como la exigencia de los requisitos mínimos para participar en unas justas deportivas, específicamente en el caso en cuestión, guardan proporción con la clase de asunto respecto del

\footnotetext{
43 CORTE CONSTITUCIONAL. Sentencia T-287 de 2013. M. P.: Nilson Pinilla Pinilla.
}

cual se convoca a los aspirantes, son exigencias razonables y no implican discriminaciones injustificadas entre las personas, pues la naturaleza de la actividad suministra por sí misma las exigencias correspondientes ${ }^{44}$.

Por todo lo anterior, la Sala finalmente se pronunció en el resuelve: 1 . Complementando las sentencias proferidas en los dos procesos acumulados, declarando en ambos casos la carencia actual de objeto; 2. Previniendo a Coldeportes para que analice si podría propiciarse: (i) que en los próximos juegos paranacionales, los deportes que queden excluidos por no reunirse el número mínimo exigido para contender, sean llevados a cabo como exhibición, con el fin de promoverlos y generar interés y apoyo hacia los mismos; (ii) que se desarrollen las acciones pertinentes en las regiones (a nivel municipal, distrital y departamental), para difundir la práctica del deporte en general, y del competitivo y de alto rendimiento en particular, como opción ocupacional y de inclusión social para las personas en situación de discapacidad.

\section{CONCLUSIONES}

Teniendo claro lo anterior, es posible afirmar que la intervención presentada por PAlls tuvo incidencia en la sentencia T-287 de 2013, toda

44 De otro lado, reiteró la importancia de las normas deportivas, específicamente las tendientes a determinar quiénes pueden participar e inscribirse en un campeonato, para confirmar y reafirmar los valores deportivos como la disciplina y el cumplimiento. Inclusive, afirmó que estimular el deporte por la vía de exigencia de los requisitos mínimos para participar en unas justas deportivas es parte de la misión educativa que el Estado mantiene a través del deporte, más si el artículo 52 de la Constitución Política se refiere a este como aspecto que repercute en el ser humano, especialmente en su educación y formación integral. 
vez que esta, en sus consideraciones, reconoció el modelo social de la Convención sobre los Derechos de Personas con Discapacidad y su carácter vinculante dentro del ordenamiento jurídico.

La intervención presentada por PAlls ante la Corte Constitucional, con referencia a los expedientes de tutela acumulados, estableció los tres postulados ya mencionados, los cuales tienen fundamento en la Convención sobre los Derechos de las Personas con Discapacidad, también definida como el primer Tratado de Derechos Humanos del siglo XXI, cuyo propósito se consagra en el artículo 1, en los siguientes términos:

Artículo uno: promover, proteger y asegurar el goce pleno y en condiciones de igualdad de todos los derechos humanos y libertades fundamentales por todas las personas con discapacidad y promover el respeto de su dignidad inherente.

Las personas con discapacidad incluyen a aquellas que tengan deficiencias físicas, mentales, intelectuales o sensoriales a largo plazo que, al interactuar con diversas barreras, puedan impedir su participación plena y efectiva en la sociedad, en igualdad de condiciones con las demás ${ }^{45}$.

En ese orden, parten de la idea del reconocimiento del "cambio de paradigma" que señala la Convención, en el sentido de un nuevo esquema que permite pensar la discapacidad como un tema de derechos, de acceso a bienes so-

45 Convención sobre los Derechos de las Personas con Discapacidad. Artículo 1. ciales, de evitar mecanismos que excluyen a este grupo de ciudadanos de espacios que son comunes a todos ${ }^{46}$, y de ver a las personas con discapacidad no como víctimas, como una minoría, como objeto de caridad ni ser tratados como enfermos necesitados de atención médica.

La Convención reconoce que la discapacidad es un concepto que evoluciona ${ }^{47}$ y que es el resultado de la interacción entre personas con diferentes niveles de funcionamiento o deficien$\operatorname{cias}^{48}$ y un entorno que no tiene en cuenta tales diferencias pues impone obstáculos, como barreras físicas y actitudes imperantes que impiden la participación en la sociedad.

Entonces, no solo reconoce la diversidad de las personas con discapacidad, sino también la necesidad de promover y proteger sus derechos humanos, bajo el entendido que siguen encontrando barreras para participar en igualdad de condiciones con las demás en la vida social, y que se siguen vulnerando sus derechos en todas partes del mundo. Por lo cual, resulta necesario un apoyo más intenso, que considere el va-

46 BROGNA, Patricia. Memorias del Seminario Internacional: Convención sobre los Derechos de las Personas con Discapacidad. Por una cultura de la implementación. México, 2007.

47 ORGANIZACIÓN DE LAS NACIONES UNIDAS. Convención sobre los Derechos de las Personas con Discapacidad. [Consultado 10 de noviembre de 2013]. Disponible en <http://www.un.org/spanish/disabilities/convention/qanda.html>

Definidas por la Organización Mundial de la Salud en la Clasificación Internacional de las Deficiencias, Discapacidades y Minusvalías, de 1980, así: la deficiencia es la exteriorización directa de las consecuencias de la enfermedad y se manifiesta tanto en los órganos del cuerpo como en sus funciones (incluidas las psicológicas). EGEA, Carlos y SARABIA, Alicia. Clasificaciones de la OMS sobre discapacidad. Murcia. 2001. [Consultado 1 de noviembre de 2013]. Disponible en <http:// www.um.es/discatif/METODOLOGIA/Egea-Sarabia_clasificaciones. pdf> 
Ior de las contribuciones que realizan y pueden realizar al bienestar general y a la diversidad de sus comunidades, así como al desarrollo económico, social y humano de la sociedad.

Con ello, da prevalencia a la autonomía e independencia individual de las personas con discapacidad, así como a la libertad de tomar sus propias decisiones, incluyendo, por tanto, su participación activa en los procesos de adopción de políticas y decisiones que los afecten, y obligando a los Estados a adoptar todas las medidas conducentes para dicho fin, haciendo las modificaciones y adaptaciones necesarias y adecuadas que no impongan una carga desproporcionada o indebida, cuando se requieran en un caso particular, para garantizar a las personas con discapacidad el goce o ejercicio, en igualdad de condiciones con las demás, de todos los derechos humanos y libertades fundamentales ${ }^{49}$.

Específicamente, impone a los Estados una carga de acción, abstención y promoción. Así, deben adoptar las medidas pertinentes, sean legislativas, administrativas y de otra índole, para hacer efectivos los derechos que les reconoce la Convención a las personas con discapacidad, implicando con ello, por un lado, modificar o derogar leyes, reglamentos, costumbres y prácticas existentes que constituyan discriminación contra estas personas, y por otro, plantear políticas y programas que consideren la protección y promoción de sus derechos. Lo anterior, primero, absteniéndose de actos o prácticas

49 Artículo 2. Convención sobre los Derechos de las Personas con Discapacidad. incompatibles con los derechos reconocidos, y velando porque las instituciones públicas, organizaciones o empresas privadas actúen conforme a lo establecido en la Convención; y segundo, promoviendo la investigación y desarrollo de bienes, servicios, equipos e instalaciones de diseño universal, así como su disponibilidad y uso, esto es, el diseño de productos, entornos, programas y servicios que puedan utilizar todas las personas, en la mayor medida posible, sin necesidad de adaptación ni diseño especializado, sin excluir las ayudas técnicas para grupos particulares de personas con discapacidad, cuando se necesiten.

Se establecen, en esa medida, compromisos para asegurar el goce de los derechos inherentes a las personas con discapacidad, así como las acciones tendientes a garantizarles el derecho a salud, educación, habilitación y rehabilitación, trabajo y empleo, nivel de vida adecuado y protección social, participación en la vida política y pública, en la vida cultural, las actividades recreativas, el esparcimiento y el deporte.

Todo esto con el objeto de eliminar las barreras que "discapacitan" a las personas, cuando distinguen, excluyen o restringen por motivos de discapacidad, con el propósito o el efecto de obstaculizar o dejar sin efecto el goce o ejercicio en igualdad de condiciones, de todos los derechos humanos y libertades fundamentales, en todos los ámbitos ${ }^{50}$. capacidad. 
Así las cosas, la intervención de PAlls sí tuvo incidencia en la sentencia T-287 de 2013, toda vez que esta reconoce el modelo social de discapacidad de la Convención sobre los Derechos de las Personas con Discapacidad, y en ese sentido las obligaciones contraídas por el Estado en cuanto a la adopción de todas las medidas necesarias, incluyendo las legislativas, para garantizar el goce pleno de todos los derechos y libertades fundamentales de las personas con diversidad funcional.

En este marco, reitera el derecho de dichas personas a participar en el diseño, implementación y puesta en marcha de políticas, programas y proyectos en que se vean involucradas o que las afecten. También, la indispensabilidad de tener en cuenta en la planeación de las medidas, los principios de diseño universal, accesibilidad y ajustes razonables, es decir, el diseño de productos, entornos, programas y servicios que puedan utilizar todas las personas, en la mayor medida posible, sin necesidad de adaptación ni diseño especializado; así como el acceso en igualdad de condiciones al entorno físico, el transporte, la información y las comunicaciones, incluidos los sistemas y las tecnologías de la información y las comunicaciones, entre otros; y finalmente, la adopción de las modificaciones y adaptaciones necesarias y adecuadas para garantizar la inclusión plena y efectiva de las personas en las diferentes esferas de la sociedad, eliminando con ello los obstáculos y barreras que las "discapacitan" y les impiden el pleno ejercicio de sus derechos.

A su vez, reafirma que dichas medidas deben promover la conciencia social, que abarca tam- bién el nivel familiar, en cuanto al respeto de los derechos y dignidad de las personas con discapacidad, propendiendo por la eliminación de estereotipos, prejuicios y prácticas que las afecten, y promoviendo el reconocimiento de sus capacidades y aportaciones, con lo cual se aparta de esquemas discriminatorios, es decir, de obstáculos, límites y restricciones de la organización estatal, de la sociedad y de sus estructuras económicas, sociales y culturales, que, de manera sutil, silenciosa y prolongada excluyan a las personas con diversidad funcional, o no reconozcan o permitan el goce de todos sus derechos.

Con lo anterior, la Corte reafirma el respeto de la dignidad inherente a la persona humana; la autonomía individual, incluida la libertad de tomar las propias decisiones; la independencia; la igualdad de todas las personas ante la ley, y en virtud de ella el derecho a igual protección sin discriminación alguna; a vivir en forma independiente y participar plenamente en todos los aspectos de la vida; al reconocimiento de su personalidad jurídica; a que se respete su integridad física y mental en igualdad de condiciones con las demás; a la libertad de expresión; y a la salud, educación, vida cultural, recreativa y deportiva. Ello, sin discriminación de ninguna índole, y sin la imposición de barreras que no permitan el ejercicio de los derechos en igualdad de condiciones con los demás.

El reconocimiento y la reafirmación que hace la Corte en la sentencia T-287 de 2013, arriba explicados, son palpables, no solo cuando dedica una aparte de sus consideraciones a los 
derechos de las personas con discapacidad y el alcance de protección de sus derechos, sino cuando, después de haberse referido a la Convención sobre los Derechos de las Personas con Discapacidad en lo atinente a su propósito, principios y obligaciones que impone a los Estados, señala que:

Por lo anterior, esta Corte reitera la condición de sujetos de especial protección constitucional de las personas en situación de discapacidad y señala que las medidas destinadas a fomentar la participación en el deporte y la recreación por parte de dichas personas deben (i) garantizar la participación de los interesados en el diseño y estructuración de los programas; (ii) tomar en cuenta los principios de diseño universal, accesibilidad para todos y todas, y ajustes razonables; (iii) promover la toma de conciencia y (iv) no construirse mediante esquemas discriminatorios.

En ese sentido, no solo reconoce el modelo social de la Convención, sino que además está adoptándolo, pues su pronunciamiento, precisamente, contribuye a la reafirmación de todos los derechos de las personas con discapacidad, al deber del Estado en pro de su garantía y protección, a la eliminación de barreras y a la toma de conciencia.

Finalmente, este pronunciamiento es un aporte valioso para el precedente judicial, vinculante en el ordenamiento jurídico colombiano, para los problemas jurídicos que se susciten en torno a los derechos de personas con discapacidad, pues dentro de la construcción de una teoría jurídica integral de las interrelaciones de varios pronunciamientos judiciales relevantes permitirá al juez o intérprete la determinación de una subregla jurídica ${ }^{51}$. En ese orden de ideas, la sentencia en cuestión es parte importante en el desarrollo lento y progresivo de real adopción del modelo social de la Convención sobre los Derechos de las Personas con discapacidad en Colombia.

Puede afirmarse que la intervención presentada por PAlls planteó tres supuestos, fundamentados en el modelo social de la Convención sobre los Derechos de las Personas con Discapacidad, que sustentan la vulneración del derecho al deporte, al libre desarrollo de la personalidad y a la igualdad de Luis Antonio Pérez Covos y Marcos Suárez Piragauta, accionantes dentro de los expedientes T-3672842 y T-3754187 acumulados, sobre los cuales la Sala Sexta de Revisión de la Corte Constitucional solicitó al Programa un pronunciamiento.

La Convención apuesta por un cambio de "paradigma" frente a la discapacidad, abandonando con ello los modelos de prescindencia y médico o rehabilitador, para crear el modelo social o de las barreras sociales. Así, la discapacidad ya no se considera un castigo o maldición, ni una enfermedad que debe ser curada, sino el efecto de las barreras con que se encuentran las personas con diversidad funcional individual al relacionarse con el entorno, en los distintos ámbitos de la sociedad. En esa medida, es la sociedad la que debe comprometerse a eliminar todos los obs-

51 LÓPEZ MEDINA, Diego Eduardo. El derecho de los jueces. Segunda Edición. Bogotá: Legis, 2006. 140 p. 
táculos y restricciones que impidan no solo el ejercicio pleno de sus derechos a las personas con alguna diversidad funcional, sino garantizar y promover su reconocimiento y respeto. Esto último, debido a que, por las concepciones que históricamente han predominado sobre la discapacidad, se ha privado del goce de derechos y libertades a las personas en comento.

Los Estados que ratificaron la Convención adquirieron un conjunto de obligaciones dirigidas a promover, proteger y asegurar el disfrute pleno y en condiciones de igualdad de todos los derechos humanos y libertades fundamentales por todas las personas con discapacidad, y a promover el respeto de su dignidad inherente.

Así lo reconoció la sentencia T-287 de 2013, en la cual la Corte resolvió el asunto de referencia, pues en ella no solo se refirió en sus consideraciones al propósito, principios y obligaciones que establece la Convención, sino que reiteró el alcance de protección de los derechos de las personas con discapacidad, reafirmando de esta manera el valor de la persona conforme el modelo social de discapacidad y haciendo un gran aporte para el precedente judicial en materia de discapacidad.

\section{Bibliografía}

ALARCOS MARTÍNEZ, Francisco. ¿Vivir dependiendo?: ética, derecho y construcción biográfica en la dependencia. Granada: Ed. Comares. 2007.
ALBA RAMÍREZ, Alonso. El empleo de las personas con discapacidad: políticas, instituciones y datos básicos. En: REDSI. Revista especializada en formación y empleo de los colectivos en riesgo de exclusión. Diciembre 2004, n. $^{\circ} 4$.

BARNES, Colin. Las teorías de la discapacidad y los orígenes de la opresión de las personas discapacitadas en la sociedad occidental. En: Barton L. (comp.). Discapacidad y Sociedad. Madrid: Ediciones Morata S. L., 1998.

BROGNA, Patricia. Memorias del seminario internacional: Convención sobre los Derechos de las Personas con Discapacidad. Por una cultura de la implementación. México, 2007.

CHARLTON, James I. Nothing about us without us: Disability Oppression and Empowerment. Los Ángeles, California: University of California Press, 1998.

COLOMBIA. CONGRESO DE LA REPÚBLICA. Ley Estatutaria 1618 "Por medio de la cual se establecen las disposiciones para garantizar el pleno ejercicio de los derechos de las personas con discapacidad". Diario Oficial n. ${ }^{\circ}$ 48.717, 27 de febrero de 2013. CORTE CONSTITUCIONAL. Sentencia C-582 de 1999. M. P.: Alejandro Martínez Caballero. . Sentencia C-625 de 1996. M. P.: Hernando Herrera Vergara. 
. Sentencia C-765 de octu-

bre 3 de 2012. M. P.: Nilson Pinilla Pinilla.

Sentencia C-804 de 2009.

M. P.: María Victoria Calle Correa.

. Sentencia T-109 de 2012.

M. P.: María Victoria Calle Correa.

. Sentencia T-139 de 2013.

M. P.: Luis Ernesto Vargas Silva.

. Sentencia T-287 de 2013.

M. P.: Nilson Pinilla Pinilla.

Sentencia T-340 de 2010.

M. P.: Juan Carlos Henao Pérez.

Sentencia T-810 de 2011.

M. P.: Mauricio González Cuervo.

. Sentencia T-977 de 2012.

M. P.: Alexei Julio Estrada.

. Sentencia T-083 de febre-

ro 11 de 2010. M. P.: Humberto Antonio Sier-

ra Porto.

CUENCA GÓMEZ, Patricia. Estudios sobre los derechos de las personas sordas. Madrid: Ed. Dykinson, 2011.

EGEA, Carlos y SARABIA, Alicia. Clasificaciones de la OMS sobre discapacidad. Murcia. 2001. [Consultado 1 de noviembre de 2013]. Disponible en <http://www.um.es/ discatif/METODOLOGIA/Egea-Sarabia_clasificaciones.pdf>
GÓMEZ BELTRÁN, Julio César. Discapacidad en Colombia: reto para la inclusión en capital humano [en línea]. Bogotá: Colombia Líder y Fundación Saldarriaga Concha, 2011. [Consultado el 10 de noviembre de 2013]. Disponible en: http://www.colombialider. org/wp-content/uploads/2011/03/discapacidad-en-colombia-reto-para-la-inclusion-encapital-humano.pdf.

LA ROTA, Miguel y SANTA, Sandra. Las personas con discapacidad en Colombia: una mirada a la luz de la Convención sobre los Derechos de las Personas con Discapacidad. Bogotá: DeJuSticia.

LÓPEZ MEDINA, Diego Eduardo. El derecho de los jueces. Segunda edición. Bogotá: Ed. Legis, 2006.

OLIVENZA. La Convención Internacional sobre Ios Derechos de las Personas con Discapacidad y su aplicación en España. Informe. [Consultado 7 de noviembre de 2013]. Disponible en: <http://www.observatoriodeladiscapacidad.es/sites/default/files/io/02_ capitulo2.pdf>

ORGANIZACIÓN DE LAS NACIONES UNIDAS. Asamblea General. Convención sobre los Derechos de las Personas con Discapacidad. Nueva York: ONU, 13 de diciembre de 2006. UNTS. Vol. 2515, p. 3. . 10 historias que el mundo debería conocer mejor. Las personas con discapacidad: un tratado que busca abrir el camino 
hacia la igualdad. [Consultado 6 de noviembre de 2013] Disponible en: <http://www. un.org/spanish/events/tenstories/2006/ story.asp?storylD $=1000>$

- Asamblea General. Resolución 31/123 del 16 de diciembre de 1996.

- Convención sobre los Derechos de las Personas con Discapacidad. [Consultado 10 de noviembre de 2013]. Disponible en: <http://www.un.org/spanish/disabilities/ convention/qanda.html>

La ONU y las personas con discapacidad: historia de la discapacidad y Naciones Unidas. [Consultado 7 de noviembre de 2013]. Disponible en: <http://www.un.org/ spanish/esa/social/disabled/disiydp.htm>

Programa de acción mundial para los impedidos. [Consultado 8 de noviembre de
2013]. Disponible en: <http://www.un.org/ esa/socdev/enable/diswps01.htm\#A>

ORGANIZACIÓN MUNDIAL DE LA SALUD Y BANCO MUNDIAL. Informe mundial sobre la discapacidad. [Consultado 7 de noviembre de 2013]. Disponible en: <http://www.who.int/ disabilities/world_report/2011/summary_ es.pdf>

PALACIOS, Agustina. El modelo social de la discapacidad: orígenes, caracterización y plasmación en la Convención Internacional sobre los Derechos de las Personas con Discapacidad. España: Ediciones Cinca, 2008.

PROGRAMA DE LAS NACIONES UNIDAS PARA EL DESARROLLO. Compendio de legislación sobre discapacidad: marco internacional, interamericano y de América Latina. [Consultado 10 de noviembre de 2013]. Disponible en: <http://conadis.salud.gob.mx/descargas/ pdf/CLSDtomo1.pdf> 